\title{
Average life prediction of existing residential buildings based on Logistic function model
}

\author{
Meng Xuyang ${ }^{1, a}$ \\ ${ }^{1}$ School of Management, Xi'an University of Architecture and Technology, Xi'an 710055, China. \\ amengxuyang90@126.com
}

Keywords: Existing buildings; prediction; average life expectancy; gross national product.

\begin{abstract}
On the energy saving of existing buildings must be used in the preparatory work, planning is the priority among priorities, analysis of what period of residential buildings for energy saving in the economy is reasonable is an important task for the planning stage, the key to the transformation of the energy saving cost for energy saving costs in both the length of the remaining life of buildings. In this paper, we hope to use the Logistic function to predict the average remaining life of existing buildings, and to be beneficial to the relevant departments.
\end{abstract}

\section{Introduction}

Building energy conservation is the urgent task of China's social and economic development, and it is a key issue that is related to the sustainable development of the country. "Five eleven" plan for the construction of our country's building energy saving cause put forward specific requirements and mission objectives, stressed that should "strict implementation of building energy efficiency design standards, and promote the construction of energy-efficient transformation, promotion of new wall materials and energy-saving products, etc. [1] so on energy saving of existing buildings must be used in the preparation, planning work is the priority among priorities, analysis of what period of residential buildings for energy saving in the economy is reasonable is an important task for the planning stage, the key to the transformation of the energy saving cost for energy saving costs in both the length of the remaining life of buildings. In this paper, we hope that we can make use of the Logistic function to predict the average remaining life of existing buildings, but it will be beneficial to the decision of the relevant departments.

\section{Model construction}

\subsection{Model selection.}

The Logistic function or Logistic curve is a common form of S function, which is named after Pierre Francois's relationship with population growth in 1844 or 1845. Generalized Logistic curves can mimic some of the $\mathrm{S}$ - shaped curves of population growth (P). At first, the exponential growth is roughly exponential; then, as the beginning becomes saturated, the increase is slow; and finally, when it reaches maturity, it stops.

If a species is moved into a new ecosystem, the number of its population will be changed. If the initial number of the species is less than the maximum capacity of the environment, then the number will increase. The species in the ecosystem are predators, food and space resources are inadequate (non-ideal environment), growth function satisfies the logistic equation, the image is in the shape of S, the equation is a mathematical model to describe the best rules under the conditions of limited resources for population growth. [2]

New housing is built in a certain range of land, and its growth rate is subject to social causes, such as population, economy, policy, etc.. So the new residential construction area has a close to the Logistic function of the constraint conditions. In a certain period of the new residential construction area, is built in a certain range, such as Jinan 1989-2009 years of new residential construction in Jinan City, new residential construction area can be used to fit the Logistic function, the construction area 
continues to increase, and finally reached saturation and began to decline, I will decline curve as a curve with the growth curve.

In this way, a certain period of the initial stage of the new housing, growth stage, mature stage, recession stage can be described. From the known Jinan in the 1989-2009 time of the new residential total construction area, can be fitted with the Logistic function with fixed parameters, the 1989-2009 time period of new residential total construction area (A) in growth period and recession period after reaching saturation difference delta y cumulative new construction area and the 2009 new residential construction area of the cumulative (B point) all the time after the recession, $t_{2}-t_{1}$ is the average life time of new residential 1989-2009.

\subsection{Model establishment.}

A large number of observational studies show that many phenomena in nature and human society, such as population, resources, and the number of animals in the ecosystem, show that the growth of $\mathrm{S}$ curves is characteristic of Logistic shape. In fact, over the years, the United Nations has predicted that the growth of the world's urbanization level, the Logistic model is the main. The problem is that the Logistic model has 3 parameters, and the usual nonlinear regression technique mainly solves the model fitting problem of the two parameters. Therefore, the scientific estimation of Logistic model parameters is the key step of the effective application of the model. Although some mathematical computing software, such as Mathcad, provides a curve fitting method for estimating the parameters of Logistic model, but because of the applicability of the algorithm is not guaranteed, the key parameter estimation results are often greatly deviated from the reality. In the process of the study, we find that the model parameters can be estimated by using multiple nonlinear autoregressive model. As long as the growth of the research object has the basic characteristics of the Logistic process, this method is effective.

Generally, the Logistic growth model can be used as a table:

$$
\mathrm{y}=\frac{y^{*}}{1+a e^{-b t}}
$$

In the formula, $\mathrm{y}^{*}$ represents the load carrying capacity or the maximum capacity, but actually reflects the saturation parameter of the growth of things. Parameter $\mathrm{y}^{*}$ is often interpreted as a measure of the number of resources, the amount of resources used to support the number of organisms. Parameter B indicates the maximum possible relative growth rate, and the value of the parameter a is determined by the ratio of the saturation value $y^{*}$ to the initial value $y 0$. When $t=0$, the a can be used as a parameter.

$$
\mathrm{a}=\frac{y^{*}}{y_{0}}-1
$$

In the practical application process, the key is to develop the saturation parameter $y^{*}$ value. In the large statistical analysis software SPSS, there is an option to fit the Logistic model: the upper bound of the growth, which is to develop the saturation parameter value. If this option is default, the default system is infinite, and the Logistic model is replaced by the exponential growth model.

Type of derivative (1) available:

$$
\frac{\mathrm{dy}}{d t}=b y\left(1-\frac{y}{y^{*}}\right)
$$

Type (1) is a special solution of the formula (3). When $y \rightarrow y 0, b \rightarrow d y /(y d t)$ is the relative growth rate of $t=0$, it is sometimes referred to as the initial growth rate of $b$. The type (3) discretization is:

$$
\frac{\Delta y_{t}}{\Delta t}=\frac{y_{t}-y_{t-1}}{\Delta t}=b y_{t-1}\left(1-\frac{y_{t-1}}{y^{*}}\right)
$$

Thus, two nonlinear auto regressive equations are obtained. One is:

$$
\Delta y_{t}=b \Delta t y_{t-1}-\frac{b \Delta t}{y^{*}} y_{t-1}^{2}
$$

The other is: 


$$
y_{t}=(1+b \Delta t) y_{t-1}-\frac{b \Delta t}{y^{*}} y_{t-1}^{2}
$$

These two auto regressive equations are equivalent in both theoretical and practical applications.

The equations (5) and (6) are nonlinear equations, but they are easily converted to linear equations, and the model parameters are estimated by linear regression analysis based on least squares. For the linear mathematical model, the model parameters can be determined by the classical least squares framework [3]. However, in the process of modeling, the transformation of the random perturbation term is often caused by the random perturbation term. So the error of the spherical normal distribution is destroyed. The linear regression analysis method is no longer appropriate. Linear regression is applied only when the data set is transformed to a constant variance.

However, for the type (5) and type (6), the linear transformation is very simple, only two square term $\mathrm{y}_{\mathrm{t}-1}^{2}$ as a variable, the model of the residual error has not been changed, so there is no such problem. In this case, we can use $\mathrm{y}_{\mathrm{t}-1}$ and $\mathrm{y}_{\mathrm{t}-1}$ as independent variables, respectively by delta $\mathrm{y}_{\mathrm{t}}$ and $\mathrm{y}_{\mathrm{t}}$ as the dependent variable, binary linear regression analysis - - nonlinear two element auto regression as nature. By means of regression analysis, two regression coefficients can be obtained.

$u=b \Delta t$ or $u=1+b \Delta t$

$v=\frac{b \Delta t}{y^{*}}$

To determine the $\mathrm{B}$ model parameters and the saturation value of $\mathrm{y}^{*}$, and then use the formula (2) parameters are obtained. So the Logistic model is built up. In most cases, the sampling time step $\mathrm{t}=1$, at this time the above formula can be further simplified. However, sometimes the delta $t=1$, but the $\mathrm{t}=10$ or other numerical. [4]

\section{Case analysis}

\subsection{Related data acquisition.}

Table 1 is Jinan City, Shandong Province, 1989-2009, a total of 1 years of new residential construction area (10000 square meters). Through the scatter plot and the preliminary fitting analysis, the data change obeys the basic characteristic of Logistic growth. Data source: Jinan Yearbook (Jinan city). 
Table 1 Jinan City, Shandong Province, a total of 21 years, a total of years of new residential construction area(million square meters)

\begin{tabular}{|c|c|c|c|c|}
\hline Year & $\begin{array}{c}\text { Total residential } \\
\text { construction area }\end{array}$ & $\begin{array}{c}\text { Reduce residential } \\
\text { construction area }\end{array}$ & $\begin{array}{l}\text { New residential } \\
\text { construction area }\end{array}$ & $\begin{array}{c}\text { Accumulative } \\
\text { total }\end{array}$ \\
\hline 1989 & 1959.00 & 32.30 & 164.50 & 164.50 \\
\hline 1990 & 2024.00 & 21.20 & 86.40 & 393.19 \\
\hline 1991 & 2098.00 & 16.90 & 75.17 & 900.84 \\
\hline 1992 & 2319.00 & 16.00 & 152.10 & 1828.69 \\
\hline 1993 & 2445.50 & 45.60 & 172.10 & 2288.69 \\
\hline 1994 & 2541.00 & 56.40 & 151.90 & 3533.80 \\
\hline 1995 & 2664.00 & 36.70 & 160.80 & 3871.80 \\
\hline 1996 & 2801.00 & 33.00 & 170.00 & 4271.80 \\
\hline 1997 & 2833.00 & 16.91 & 49.38 & 4557.80 \\
\hline 1998 & 2902.00 & 24.84 & 93.80 & 4842.80 \\
\hline 1999 & 3180.00 & 22.80 & 300.00 & 5142.80 \\
\hline 2000 & 3435.00 & 30.00 & 285.00 & 5236.60 \\
\hline 2001 & 3675.00 & 46.00 & 286.00 & 5285.98 \\
\hline 2002 & 4045.00 & 30.00 & 400.00 & 5455.98 \\
\hline 2003 & 4366.00 & 17.00 & 338.00 & 5616.78 \\
\hline 2004 & 5508.74 & 102.37 & 1245.11 & 5768.68 \\
\hline 2005 & 6195.00 & 89.00 & 460.00 & 5940.78 \\
\hline 2006 & 7097.27 & 25.93 & 927.85 & 6092.88 \\
\hline 2007 & 7551.49 & 53.43 & 507.65 & 6168.05 \\
\hline 2008 & 7713.88 & 66.30 & 228.69 & 6254.45 \\
\hline 2009 & 7810.40 & 101.49 & 164.60 & 6418.95 \\
\hline
\end{tabular}

\subsection{Data processing.}

Starting from the original data, can generate 4 sets of data, or 4 variables: Pt- 1 for 1989-2008 years of total new residential construction area (10000 square meters); P2t-1 1989-2008 accumulated over the years new residential construction area of the square; $P_{t}$ for the calendar year 1990-2009 total new residential construction area; $\mathrm{P}_{\mathrm{t}}=\mathrm{P}_{\mathrm{t}}-\mathrm{P}_{\mathrm{t}-1}$ 1989-2009 over the years cumulative new residential construction area difference value.

\subsection{Multivariate nonlinear regression analysis.}

First of all, P said total new residential construction area (10000 square meters), instead of type (5) in $\mathrm{Y}$, considering the time step $\mathrm{t}=1$, obtained from the regression equation.

$$
\Delta P_{t}=b P_{t-1}-\frac{b}{P^{*}} P_{t-1}^{2}
$$

The sequence of $\mathrm{P}_{\mathrm{t}-1}$ and $\mathrm{P}_{\mathrm{t}-1}$ as two independent variables and the dependent variable differential sequence $\mathrm{P}_{\mathrm{t}}=\mathrm{P}_{\mathrm{t}}-\mathrm{P}_{\mathrm{t}-1}$, can be binary linear regression analysis. Note that equation intercept is 0 , so the calculation when the constant is 0 . The regression results are shown in Table 2, at the significance level alpha $=0.05$, $\mathrm{R}$ value of the correlation coefficient, standard error, $\mathrm{F}$ statistic and t statistic are passed by.

Table 2 The multi variable nonlinear regression results based on differential sequence for $\mathrm{P}_{\mathrm{t}}$ 


\subsection{Determine the form of Logistic function.}

According to this result, the regression coefficient is $\mathrm{b}=0.3192, \mathrm{~b} / \mathrm{P}^{*}=0.000043$. So the estimation result of saturation parameter is $\mathrm{P}^{*}=0.3192 / 0.000043=7423, \mathrm{a}=44.12$.

So the establishment of Logistic forecast model is as follows:

$$
P_{t}=\frac{7423}{1+44.12 e^{-0.3192 t}}
$$

\section{5 calculated average life}

From the formula, the total new residential construction area of 74 million 230 thousand square meters. 2009 the cumulative increase in residential construction area of square meters, to grow to 74 million 230 thousand square meters, 10 million 40 thousand square meters, the need for nearly 4 years.

1004 into the formula 10 , obtained $t=6$. Because of the use of symmetry has been derived from the cumulative increase in residential construction area of recession graphics (growth figures and recession graphics approximation in $\mathrm{x}=24$ axis symmetry).

According to graphics, the cumulative total of new residential construction area from square meters (t1=9) growth and then decline to 10 million 40 thousand square meters ( $\mathrm{t} 2=39.95)$ also takes 30.95 years. That is, the average life expectancy of the new residential buildings in Ji'nan is 30.95 years 1989-2009.

\section{Summary}

Through the prediction of Jinan province Shandong 1989-2009 years of new residential construction life is only 31 years, but according to China's "civil architectural design general rule", the main building and high-rise building structure of the main structure is 100 years, the general

\begin{tabular}{|c|c|c|c|c|c|c|c|}
\hline \multicolumn{8}{|c|}{ Regression statistics } \\
\hline Multiple & 0.97054 & & & & & & \\
\hline R Square & 0.95784 & & & & & & \\
\hline Adjusted & 0.68478 & & & & & & \\
\hline $\begin{array}{l}\text { standard } \\
\text { error }\end{array}$ & 227.535 & & & & & & \\
\hline $\begin{array}{l}\text { observed } \\
\text { value }\end{array}$ & 19 & & & & & & \\
\hline \multicolumn{8}{|l|}{$\begin{array}{l}\text { Analysis of } \\
\text { variance }\end{array}$} \\
\hline & df & SS & MS & $\mathrm{F}$ & Significance F & & \\
\hline $\begin{array}{l}\text { Regression } \\
\text { analysis }\end{array}$ & 2 & 2754509 & 1377255 & 26.6021 & 8.16E-06 & & \\
\hline Residual & 17 & 880130 & 51772.4 & & & & \\
\hline $\begin{array}{c}\text { Total } \\
\text { Coefficients }\end{array}$ & 19 & $\begin{array}{c}3634640 \\
\text { standard } \\
\text { error }\end{array}$ & t Stat & P-value & Lower95\% & Upper95\% & lower 95\% \\
\hline Intercept & 0 & \#N/A & \#N/A & \#N/A & \#N/A & \#N/A & \#N/A \\
\hline 164.5 & 0.319196 & 0.05819 & 5.48457 & $4.028 \mathrm{E}-05$ & 0.196407 & 0.44198 & 0.19640 \\
\hline 27060.25 & $-4.3 \mathrm{E}-05$ & 1.13E-05 & -3.82431 & 0.0013572 & $-6.7 \mathrm{E}-05$ & $-1.9 \mathrm{E}-05$ & $-6.7 \mathrm{E}-05$ \\
\hline
\end{tabular}

building for $100 \sim 50$ years. Far from the design of useful life. I think the reasons are as follows:

The government departments of the planning and design level to be improved, resulting in the planning and design is not reasonable, easy to cause the use of buildings can be removed. On the lack of supervision of the developers, approval is not strict enough.Developers, the pursuit of the interests of the interests of the maximum, reducing the comfort of residential requirements, such as high volume rate, green rate is too low, so that people continue to move away from. Finally, the service life is shortened. Some builders, builders cut corners, such as the completion of the wall is just caused by the cracking problem in the residential life itself in the beginning is shortened. 


\section{Acknowledgement}

This work is supported by National Soft Science Foundation of China (Grant No. 2013GXS4D152), Humanities and Social Sciences Foundation of Ministry of Education of China (Grant No. 14YJA790090), Shaanxi Province Soft Science Foundation (Grant No. 2012KRM100).

\section{References}

[1] Lin Ju, Chen Yang, Sun Shenggen, Zhao Hong. Both comprehensive exploration and practice of [J]. residential renovation of residential energy-saving technology, 2006,7:24-28.

[2] Iran - Prigogine; Zeng Qinghong, Shen Xiaofeng translated from chaos to order [M]. Shanghai: Shanghai Translation Publishing House, 2005:192.

[3]Bates DM, G. NonlinearRegressionAnalysis and ItsApplications[M] New. York: JohnWiley\& Sons WattsD, 1988

[4] Chen Yanguang. Self regression estimation of Logistic model carrying capacity parameters in population and resource prediction [J]. Journal of natural resources, 2009,6 (24): 1105-1114.

[5] Yuan Wei et al. Statistics [M]. Beijing: Higher Education Press, 2000

[6] Ji'nan City, city of love, http://www.jnsq.org.cn/

[7] Mao Shisong, Zhou Jixiang. Probability theory and mathematical statistics [M]. Beijing: China Statistics Press, 2000

[8] Liu Xiaojun, Ouyang Jiantao. Research on the life cycle of China's [J]. industry technology and economy, 2007,5.

[9] Song Zongyun. Study on the life of our country and the study of [J]. technology, 2012 (2): 176 